\title{
¿DE UNA ESPAÑA VIRIL A UNA ESPAÑA TRAVESTI? TRANSGRESIÓN TRANSGÉNERO Y SUBVERSIÓN DEL PODER FRANQUISTA EN LA TRANSICIÓN ESPAÑOLA HACIA LA DEMOCRACIA*
}

\begin{abstract}
MERCÈ PiCORNELL
LiCETCT. Universitat de les Illes Balears

Recibido: $19 / 04 / 2010$

Aceptado: $1 / 11 / 2010$

\section{Resumen}

Este artículo propone una reflexión sobre la función política de la imagen del travesti en el contexto español durante la transición del franquismo a la democracia. En concreto, se analiza cómo en la prensa contracultural de los setenta, lo travesti no se presenta como una práctica ni una opción, sino más bien como un símbolo de contrapoder monolítico que permite ejemplificar públicamente la clausura de la «virilidad» del poder franquista sin afirmar todavía plenamente una nueva identidad democrática. Resulta, por lo tanto, un correlato útil para visibilizar la necesidad de celebrar la posibilidad de subversión, de eliminar las huellas que el poder franquista pueda haber impreso, no sólo en las instituciones, sino también en la percepción de la propia identidad o las posibilidades de ocupar el espacio público. Así mismo, se estudia cómo esta subversión parece perder su sentido una vez ya está asentado un nuevo poder, esta vez democrático, y cómo el destape -la profusión de imágenes sexuales en
\end{abstract}

\footnotetext{
* Este artículo se inscribe en el marco del proyecto FFI2009-07086 y supone la ampliación y revisión de las tesis expuestas en un estadio inicial en dos comunicaciones inéditas presentadas en el XII International Colloquium of the North American Catalan Society, R/Evolution in Catalan Culture and the Arts. Halifax (Canadá), Dalhouise University (2007); y en el «IV Congreso Iberoamericano de Estudios de Género», Universitat de les Illes Balears y Universidad Nacional de Rosario (2008). Su redacción final ha sido realizada durante la estancia en el Fitzwilliam College, University of Cambridge, gracias a una beca José Castillejo (Ministerio de Ciencia e Innovación, 2009-2010).
}

Feminismo/s 16, diciembre 2010, pp. 281-304 
los productos de consumo a finales de los setenta- contribuye a esta desactivación de la capacidad revulsiva del símbolo.

Palabras clave: poder, transición, destape, identidad transgénero, contracultura, subversión.

\begin{abstract}
This paper explores the political function assigned to transgender identities in the context of the Spanish transition from francoism to democracy. It focuses on how Spanish underground journals of the seventies use the image of the transgender community as a symbol of subversion that exemplifies the end of the "virility» that francoism had associated with power. Transgender identities are used as a monolithic symbol of the need of celebrating subversion, of deconstructing the influence of francoist power in the construction of identities, but also as a symbol of the new possibility of reclaiming public space. The paper also analyses how this subversion seems to loose its sense once democracy is instituted, and how the destape -the profusion of sexual images in the cultural products of the late seventies in Spain-is related to this loss of revolutionary potential linked to transgender practice.
\end{abstract}

Keywords: Power, Transition, destape, Transgender Identities, Underground Culture, Subversion. 
En el apéndice documental del catálogo de la exposición retrospectiva que, en el año 2002 reunió cómics y pinturas de Nazario, aparece reproducida su foto -de frente y de perfil- en una curiosa ficha policial donde su poblado bigote no puede esconder una cara de absoluta estupefacción, fácilmente comprensible cuando observamos que, frente al formalismo serio de la ficha, destaca la indumentaria del dibujante: un estrafalario vestido con volantes. La ficha corresponde a la detención por escándalo público de Nazario junto con su amigo José Ocaña, también pintor, el 5 de julio de 1978, fecha en la que la Ley de Peligrosidad Social, instaurada por el régimen franquista, todavía seguía vigente $^{1}$. La imagen travestida de Nazario distorsiona el sentido de la misma ficha policial, encargada de fijar y controlar una identidad considerada delictiva, mediante la intromisión de una diferencia ostentosa, escandalosa en su visibilidad, provocadora en el contraste que propone la presencia simultánea, sobre un solo cuerpo, del bigote y el vestido. La coincidencia de elementos convencionalmente considerados femeninos y masculinos en la identidad que se pretende fichar pervierte el mismo sentido del documento policial, haciéndolo susceptible de una lectura irónica, convirtiéndolo en muestra de la caducidad de los instrumentos represivos de un régimen, el franquista, que había utilizado la virilidad como símbolo de su poder, como atributo indispensable del ejercicio de su autoridad.

En este artículo me propongo reflexionar sobre cómo, en el momento liminar que marcan los años 1975 a 1978, la imagen del travesti (siempre en forma de hombre vestido de mujer) deviene una metáfora recurrente de la transición política entre la dictadura franquista y un nuevo estado democrático todavía en proceso de definición. Veremos cómo el travesti es presentado en las páginas de las revistas contraculturales del momento como una identidad en transición que, desde su posición ambigua, permite mostrar las fisuras de un poder en crisis. Se trata, además, de una transgresión sobre el poder

1. La Ley de Peligrosidad y Rehabilitación Social (Ley 16/1970) se había ampliado el año 1974 (Ley 43/1974) y sería muy cuestionada durante la segunda mitad del 1978, año en el que sus artículos más polémicos -entre los cuales los referidos a la homosexualidad- serían anulados. La Ley seguiría vigente hasta la aprobación el año 1995 del nuevo Código Penal (Ley Orgánica 10/1995).

Feminismo/s 16, diciembre 2010, pp. 281-304 
franquista que entiende el poder no únicamente como una autoridad que «se ejerce» sino también en el sentido relacional e incisivo que le otorgaba Michel Foucault, como consecuencia de una situación estratégica compleja que provoca una interiorización de las normas sociales. Escenificando la posibilidad de confusión de las atribuciones de género, el travesti como símbolo pretende desnaturalizar el arraigo de un poder no solo ejercido desde las instituciones que la democracia desmantelará sino también inscrito de una manera más sutil, en forma de modelos de identidad. Como han argumentado desde posiciones diferentes Foucault y Bourdieu ${ }^{2}$, el poder se interioriza hasta el punto de penetrar en nuestras propias identidades, de condicionar la percepción de nuestros propios cuerpos. Reescribir desde la performance travesti los significados (sexuados) que el poder atribuye a los cuerpos puede ser una forma de hacer pública su convencionalidad, una estrategia que, si bien, como notaba Bourdieu $^{3}$, no propone un plan de acción decisivo con el que desmantelar de raíz las estructuras de dominación simbólica, sí que provoca una crisis en los modelos de representación, abre fisuras para que nuevas formas de poder y de identidad puedan afirmarse.

Como ha notado Patrick Paul Garlinger, en algunos estudios recientes sobre la cultura española posfranquista, el travesti ha sido tratado como el icono de una transición representada como una ruptura limpia entre épocas más que como un proceso complejo ${ }^{4}$. Esta interpretación de la práctica travesti como símbolo de ruptura -representado en los Estudios Culturales hispánicos por la figura de Ocaña o por los personajes transgénero que circulan por las películas de Almodóvar- se produce a menudo descontextualizada respecto al marco contracultural donde se había justificado su función. Así, fuera de contexto, es cuando el travesti puede convertirse en símbolo de un límite claro entre dos estados, y no en la representación de una forma ambigua y compleja de transición entre instituciones de poder. Esta doble posibilidad de interpretación opone dos percepciones diferentes sobre la identidad transgénero: la que la entiende como frontera entre el ser hombre o el ser mujer y la que la concibe como espacio de transición en un continuum de identidades de género que solo se fijan convencionalmente. Permite, así mismo, en su

2. Sobre la interiorización del efecto del poder, ver especialmente las declaraciones de Michel FOUCAULT en «Les rapports de pouvoir passent à l'intérieur des corps», compilada en Dits et écrits: 1954-1988. París, Galimard, 2004, pp. 228-236; así como BouRdieu, Pierre. La dominación masculina. Barcelona, Anagrama, 2000 (1998).

3. Bourdieu, Op. Cit., p. 127.

4. Garlinger, Patrick Paul. «Dragging Spain into the Post-Franco's Era: Transvestism and National identity in Una mala noche la tiene cualquiera». Revista Canadiense de Estudios Hispánicos, XVIV: 2 (2000), pp. 363-381. 
sentido alegórico, contraponer dos visiones divergentes sobre el mismo proceso político de superación de la dictadura: la que percibe la transición como una ruptura entre dos sistemas de poder que provoca plenamente la anulación del franquismo, y la que la considera un simulacro de cambio democrático que presenta numerosas continuidades respecto al régimen anterior.

En las siguientes páginas, se encontrarán algunas notas de lectura sobre el contexto inicial en el que se produce esta apropiación simbólica de la imagen del travesti recogidas en la prensa barcelonesa y valenciana de los años que siguen la muerte de Franco. Organizaré mi exposición en cuatro apartados. Reflexionaré, en primer lugar, sobre el uso de lo transgénero como escenificación de la ruptura del vínculo franquista entre virilidad y poder, un uso que provoca una apropiación del travesti como icono político del cambio. En el segundo y el tercer apartado, consideraré cómo este travesti apropiado parece operativo políticamente sólo si es capaz de escenificar su ambigüedad, y cómo, desde esta escenificación, es utilizado para reflexionar sobre la necesidad de difuminar la frontera entre la vida privada y el espacio público. Para terminar, reflexionaré, desde las declaraciones de José Ocaña en la prensa contracultural del momento, sobre el carácter estratégico de su uso del transvestismo y los riesgos de domesticar su subversión, es decir, de integrarse en un nuevo estado democrático que necesita permitir algunas subversiones controladas para diferenciarse simbólicamente del estado anterior. Propongo, en definitiva, un recorrido parcial por los usos simbólicos de la categoría «travesti» en la España de la transición, una categoría intermedia (in-between, por usar el término difundido por Homi Bhabha ${ }^{5}$ ), apropiada tanto para escenificar la ruptura con el ideario franquista como la dificultad de la democracia de instaurarse como espacio de plena libertad.

\section{Identidad e impostura: las máscaras sexuadas del poder}

Para el régimen franquista, la oposición feminidad/virilidad había resultado un espacio simbólico donde sostener los parámetros morales del régimen ${ }^{6}$. En contra de la «perniciosa inversión» de roles que habían empezado a proponer las feministas españolas de los años veinte y treinta, Pilar Primo de Rivera,

5. BHABHA, Homi. The Location of Culture. Londres, Routledge, 2004.

6. Ver al respecto GALLEGO MÉNDEZ, María Teresa. Mujer, falange y franquismo. Madrid, Taurus, 1983; GonZÁLEZ AJA, Teresa. «Monje y soldado. La imagen masculina durante el Franquismo». Revista Internacional de Ciencias del Deporte, 1 (2005), pp. 64-83; PÉREZSÁNCHEZ, Gema. «El Franquismo ¿un régimen homosexual?». Orientaciones, 7 (2002), pp. 29-48 o VINCENT, Mary. «La reafirmación de la masculinidad en la cruzada franquista». Cuadernos de Historia Contemporánea, 28 (2006), pp. 135-151.

Feminismo/s 16, diciembre 2010, pp. 281-304 
delegada nacional de la Sección Femenina de Falange Española y de las JONS, afirmaba el año 1939 que «la única misión que tiene asignada [la mujer] en la tarea de la Patria es el hogar» ${ }^{7}$, y Dionisio Ridruejo pretendía aportar un trasfondo intelectual a la idea cuando afirmaba en su discurso en el Tercer Consejo Nacional de la Sección Femenina que «a la mujer le corresponde un destino de sumisión, de docilidad $»^{8}$. Frente a este «destino de docilidad» femenino, el de España era un destino caracterizado recursivamente en los discursos franquistas como «viril». «Queremos la vida dura, la vida difícil, la vida de los pueblos viriles», afirmaba Franco en su discurso en ocasión del primer aniversario del inicio de la rebelión militar; España, añadía, tenía que ser un país «con pulso y virilidad $»^{9}$. Como ha explicado Mary Vincent, esta imagen sexuada del poder convertía el cuerpo masculino en objeto tanto de exaltación como de vigilancia, ya que de él «dependía» no solo la regeneración de la raza sino también la estabilidad de la «gran familia» española que el «caudillo» debía controlar como un padre vigilante y severo ${ }^{10}$.

Así vistas las cosas, atentar contra los valores que el régimen atribuía a «la virilidad» era simbólicamente atentar contra la España de Franco y contra las estructuras que mantenían su poder. En este contexto se entiende quizás la especial preocupación del régimen por perseguir la homosexualidad -anatemizada como supuesto atentado al concepto franquista de lo viril- así como su progresiva consideración, en función de la evolución del régimen, como pecado, enfermedad, delincuencia y peligro social ${ }^{11}$. En 1954, el gobierno de Franco modificaría la Ley de Vagos y Maleantes de 1933 para incluir a los «homosexuales, rufianes y proxenetas» entre los condenables a realizar estancias de reeducación en prisiones y en las denominadas «Casas de Templanza» por un tiempo que se presentaba en el texto legislativo como «absolutamente indeterminado» ${ }^{12}$. Sin embargo, parece ser que el poder «viril» de España no dejaba de verse amenazado y, todavía durante los años sesenta,

7. Gallego MÉndez, María Teresa. Op. Cit., p. 89.

8. Ibid, p. 181.

9. GONZÁlez AJA, Teresa. Op. Cit., p. 7.

10. Argumenta Mary VINCENT: «la autoridad varonil dependía de una identidad corporal -la existencia de los hombres dentro de un cuerpo sexuado- aunque ese mismo cuerpo fuera a la vez una fuente de la corrupción y decadencia que debían ser resistidas» (Op. Cit., p. 139).

11. Para un estudio de la represión de la homosexualidad durante el franquismo ver OLMEDA, Fernando. El látigo y la pluma. Homosexuales en la España de Franco. Madrid, Oberon, 2004 y UGARTE, Javier. «Entre el pecado y la enfermedad». Orientaciones, 7 (2004), pp. 7-26.

12. Ver la Ley de Vagos y Maleantes, de 4 de agosto de 1933, con extensión de 15 de julio de 1954. 
el régimen producía libros con títulos tan prometedores como La virilidad y sus fundamentos sexuales (1962), del médico y jesuita Federico Arvesu, o Gamberros, homosexuales, vagos y maleantes (1962), del magistrado barcelonés Antonio Sabater. En 1970, la Ley de Peligrosidad Social cambiaría la condena a los «homosexuales» para incluir la paráfrasis «los que realicen actos de homosexualidad $»^{13}$, modificación aparentemente más restringida pero, en realidad, poco inocente, ya que anula la posibilidad de concebir la homosexualidad como «identidad» en un momento en el que en el ámbito internacional emerge como sujeto de reivindicación política. Nace también con esta ley una nueva categoría, la de los «peligrosos sociales», un término que será reutilizado en los medios alternativos para crear un nuevo sujeto colectivo de lucha que se define bajo la rúbrica común de la marginación y que se representará a menudo con la imagen de un travesti. Así, por ejemplo, la revista contracultural valenciana Los Marginados dedica un monográfico el año 1977 a «los peligrosos sociales», y en la portada podemos ver en primer plano la cara de un hombre maquillado. Nazario, para representarlos, dibujará una divertida «Miss Peligrosidad Social», travestida y con barba que exclama provocativa y contenta «Dicen que para nosotras todo el año es carnaval $»^{14}$.

El travesti, de hecho, supone no sólo una transgresión simbólica del modelo de virilidad franquista, sino que toma forma en tanto que su subversión se exterioriza, sea en la calle, en un espectáculo o únicamente ante la mirada cómplice del espejo. Es por esto que al de «peligroso social», al travesti también se le podía añadir el delito de «escándalo público». Quizás sea esta doble delictividad respecto al régimen franquista lo que convierte al travesti en un icono apropiado de la subversión del poder establecido en los monográficos y artículos que, especialmente durante los años 1977 y 1978, dedican al tema diversas revistas editadas en Barcelona y Valencia. En este contexto, el travesti no solo supone, como afirma Toni Puig en la revista Ajoblanco, una parodia del «femenino oficializado» sino que resulta un portavoz idóneo de múltiples transgresiones ${ }^{15}$. Así lo considera Jordi Mesalles, quien afirma en un artículo para El Viejo Topo que «El travesti supera distancias como portavoz que habla a partir de significar la objectualización erótica de la mujer» ${ }^{16}$. Hablaremos más adelante de este uso objetualizado de la imagen de la mujer. Me interesa de momento atender al uso del travesti como portavoz de una oposición al poder cuya práctica se va cargando de diferentes sentidos no necesariamente

13. Ver la Ley de Peligrosidad y Rehabilitación Social, de 4 de agosto de 1970.

14. Ver LuQue, Nazario [Nazario]. Plaza Real. Madrid, Vossa, 1995.

15. PUIG, Toni. «Yo también soy travesti». Ajoblanco, 19 (1977), pp. 13-16.

16. MeSAlles, Jordi. «Travesti: gesto y deseo». El Viejo Topo, 12 (1977), pp. 64-66.

Feminismo/s 16, diciembre 2010, pp. 281-304 
relacionados con las políticas de género sino también con la disolución de la estructura simbólica del poder franquista ${ }^{17}$. Así, por ejemplo, en la revista valenciana Los Marginados, Benigno Camañas caracteriza el travesti como un «quiste [que surge] en el mismo corazón del orgullo macho», a lo que añade:

El travestí es el radical de la política sexual, el etarra que desestabiliza con la provocación de su ambigua presencia. Desata el deseo, inquietando con su falo bajo las faldas, con sus pelos bajo el maquillaje. Fuerza la situación procurando el choque, hasta límites no integrables por los cauces normales» ${ }^{18}$.

La comparación del travesti con un terrorista en el contexto español de finales de los setenta, en el que la banda ETA estaba más activa que nunca, es especialmente revulsiva. El «choque» que provoca el travesti lo convierte en un radical en boca del cual difundir la necesidad de cambio. Así ocurre, por ejemplo, en un reportaje que Fernado Albertí publicaría en la revista valenciana Dos y Dos el año 1977, titulado «Travestis que hacen país», y destinado no tanto a dar la voz a los travestis entrevistados para que expliquen su práctica como a insistir en el ideario autonomista que pueden contribuir a difundir. Explica Albertí que Encarnita, miembro del Front d'Alliberament Gai y del Partit Socialista del País Valencià, alude en sus espectáculos «a los problemas específicos del País Valencià: la polémica valenciano-catalán, el estatuto, el centralismo...» ${ }^{19}$. Y afirma la implicada: «Personalmente, yo trato de combatir desde aquí la discriminación sexista, los tabús y la represión de estos cuarenta años, haciendo también que el espectador tome consciencia de otros problemas: los problemas del País Valencià, en definitiva». Se nos explica que también la Champán «monta sus números sobre el machismo y la comodidad burguesa, y afirma su voluntad de participar en los movimientos autonomistas». En suma, concluye el entrevistador, se trata de profesionales que pretenden con su tarea «contribuir a transformar la sociedad [...] con tanta vocación nacionalista o estatutaria como el que más ${ }^{20}$.

El travesti parece haberse convertido en un símbolo que puede absorber múltiples reivindicaciones de oposición al poder establecido. Nos encontramos quizás ante una reocupación o apropiación de la capacidad subversiva que Judith Butler atribuía a la práctica transformista de los drags, a su

17. Escribe al respecto Teresa VILARÓs: «En el espejo se reflejan especularmente una serie de compuestos: máscaras y travestidos, historias y plumas, simulacros y prótesis que forman el 'yo' fragmentado de la postdicatdura, un 'yo' colectivo que busca ante todo y sobre todo la disolución» (El mono del desencanto. Una crítica cultural de la transición española (1973-1993). Madrid, Siglo XXI, 1998, p. 218).

18. CAMAÑAS, Benigno. «El travestismo resucita». Los Marginados, 8 (1978), pp. 30-31.

19. AlberTí, Fernando. «Travestis que hacen país». Dos y Dos, 50 (1977), p. 38.

20. Ibid, pp. 38-39. 
potencial para escenificar desde la parodia el carácter performativo de cualquier identidad de género ${ }^{21}$. Esta apropiación del travesti como símbolo lleva en 1978 a Toni Puig a afirmar con entusiasmo en las páginas de Ajoblanco «Yo también soy travesti» en un artículo donde el travesti deviene plenamente una figura que encarna la posibilidad de romper con la «normalidad caduca» en la que vive la sociedad española. El artículo de Puig es de tono casi épico:

Adorables e ignotos travestis. Caballos galopantes en el universo de lo prohibido y codiciado. Perversos destructores de toda norma y seguridad. Sorprendentes en el amor. Fantásticos en el maridaje de los sexos. En vosotros se aúna el placer, la pasión, la anormalidad, la imaginación, el desconcierto, la frivolidad y la subversión corporal. Estáis más alejados que cualquier otro en lo real y simbólico- de ese afán por clasificarlo y dilucidarlo todo. Vivís del placer. Estáis más allá del sexo y de toda cultura. En subversión continua22 ${ }^{22}$

La identidad del travesti es para Puig la del que está en subversión continua respecto a una sociedad en la que, en el fondo, todos representamos un papel. Es por este motivo que resulta necesario asumir su modelo de revuelta entendida ya en un nivel puramente simbólico:

No. No es necesario que te pongas faldas. Y a lo loco. Urge que comprendamos y practiquemos lo que el transvestismo proclama: la inversión total de los valores a los que por aprendizaje estamos tan acostumbrados. Hoy, el travestí continúa siendo la crítica más subversiva. A pesar, incluso, de plantearse en un campo aparentemente apolítico. Y una subversión en exceso. Proponerte el travestismo como lucha, majo, como método, significa batallar en los campos más inmediatos por hacer estallar ese disfraz de esclerosidad en la opresión en la que nos hallamos metidos y en la que tan a gusto funciona la sociedad. Significa denunciar y barrer las máscaras de la comedia, los fingimientos, lo archifalso de nuestra relaciones sociales, políticas, jerárquicas ${ }^{23}$.

21. Considera Judith BUTLER: «drag fully subverts the distinction between inner and outer psychic space and effectively mocks both the expressive model of gender and the notion of a true gender identity». Y un poco más adelante: "The performance of drag plays upon the distinction between the anatomy of the performer, and both of those are distinct from the gender of the performance, the performance suggest a dissonance not only between sex and performance, but sex and gender and gender and performance. As much as drag creates a unified picture of 'woman' (what its critics often oppose), it also reveals the distinctness of those aspects of gendered experience which are falsely naturalized as a unity through the regulatory fiction of heterosexual coherence. In imitating gender, drag implicitly reveals the imitative structure of gender itself -as well as its contingency» (Gender Trouble. Feminism and the Subversion of Identity. New York, Routledge, 1990, pp. 174-175).

22. PUIG, Toni. Op. Cit., p. 13.

23. Ibíd, p. 15.

Feminismo/s 16, diciembre 2010, pp. 281-304 
La simulación del travesti permite denunciar las máscaras del poder. Es también, afirma, un espacio aparentemente apolítico en un momento, el de la transición hacia la democracia, en el que la política ya está pasando de la resistencia cívica a la dinámica de partidos ${ }^{24}$. Quizás sea esta aparente apoliticidad que menciona Puig lo que permite la apropiación del travesti como símbolo de una oposición radical frente al poder en decadencia. Se trata, sin embargo, de una apropiación algo perversa en tanto que no define la transgresión transgénero como una opción o como una práctica que tenga sentido en ella misma, sino como un emblema vacío del contrapoder que es posible llenar de distintos significados, como una nueva máscara desde la que emitir juicios y posturas radicales que quizás todavía no es del todo seguro expresar «en propia voz».

\section{Políticas perversas: el destape y la impostura}

Pasando revista a la prensa contracultural, dos contextos más nos permiten explicar también esta reutilización simbólica del travesti para la representación de las fisuras de un poder en decadencia. Estos se refieren, en primer lugar, a la aparente «liberación sexual» que debería permitir la clausura del franquismo y, en segundo lugar, a una erosión del concepto tradicional de virilidad que el travestismo permitiría poner de manifiesto. En el primer sentido, el travesti se presenta como la cara politizada y alternativa de un «destape» quizás inevitable después de años de represión y censura. El «destape», es decir, la profusión de cuerpos femeninos semidesnudos y escenas de sexo en las revistas y películas del posfranquismo, fue visto como uno de los símbolos de la permisibilidad del nuevo estado sin censuras, un camino hacia una supuesta liberación sexual que, como ya denunciaban el año 1978 Alberto Cardín y Federico Jiménez-Losantos en la introducción de su libro La revolución teórica de la pornografía, era más aparente que real y, sobretodo, estaba exclusivamente dirigida a un público masculino heterosexual ${ }^{25}$. Durante los años del «destape», los monográficos sobre sexualidad y, específicamente, sobre

24. Explica Teresa VILARós diferenciando el proceso de escenificación de la libertad sexual en España del movimiento de coming out americano de los setenta y ochenta: «La 'salida' española en el período de la transición responde, sin embargo a otro pasado y a otra tradición. La pluma en la España recién salida del franquismo rechaza las categorías de identidad; y aunque asume, se presenta y se enmarca en el mismo paradigma global que permite su salida, evita de forma apasionada cualquier forma institucionalizada de participación política» (Op. Cit., p. 185).

25. CARDín, Alberto; JimÉNEZ-LOSANTOS, Federico. La revolución teórica de la pornografía. Barcelona, Iniciativas Editoriales, 1978, pp. 9-24. 
la necesidad de liberarse de coacciones morales en cuestiones sexuales inundan las revistas contraculturales: «No hay perversión que valga» afirma Josep Maria Farré, médico del Departamento de Psiquiatría del Hospital Clínico de Barcelona, en una entrevista que publica en 1978 Ajoblanco; «El que tenga una perversión, que la cuide, que la cuide...» se titula una de las secciones del especial «sexualidad» de la misma revista, que se inicia con una cita de Marcuse: «La sexualidad es por naturaleza polimorfa, perversa» y que incluye un «Diccionario-guía de perversiones e inventario de aberraciones». El perverso, se afirma, es en realidad un gourmet del $\mathrm{sexo}^{26}$. En el mismo marco de reversión del sentido de la «perversión» resultan muy interesantes las crónicas firmadas por Joan Seté en la revista Los Marginados, donde, por ejemplo, dedica un divertido y documentado reportaje a la historia del exhibicionismo y a su prohibición como fórmula de mitificación del papel del falo, aplicando su análisis a distintas sentencias judiciales coetáneas dictadas contra los «perversos». El exhibicionismo, expone Joan Seté, es una perversión que sólo pueden «practicar» los hombres:

¿Cómo penar a una señora abierta de piernas en un escenario o una esquina? ¿Quién es el macho que se atreve a formular denuncia diciendo que le excita? Normal. Un hombre debe excitarse ante la vista de la teta derecha de fulanita y el entrecote de menganita. La mujer está hecha para eso: para excitar. [...] ¿Quién es el macho que se atreve a formular denuncia diciendo que la teta izquierda de menganita no le excita? ${ }^{27}$

La visibilidad sexual de la mujer, su constante disponibilidad para el «servicio sexual forzoso», como diría Monique Wittig en «La categoría de sexo», condiciona la vinculación entre virilidad y exhibicionismo, un vínculo que aumenta todavía el potencial transgresor del travesti que, siendo hombre, se exhibe desde su feminidad ${ }^{28}$.

En el segundo sentido, la decadencia de los discursos tradicionales sobre la masculinidad y la feminidad se irá concretando como tema de discusión en estas mismas revistas sobre todo a principios de los años ochenta. En el dossier que El Viejo Topo dedica a «El macho en crisis» (1980), se discute la necesidad de emergencia de los nuevos discursos sobre la masculinidad paralelos a la consolidación del movimiento feminista en la España del posfranquismo. La crisis de la «masculinidad» aparece ligada, así mismo, a los discursos sobre

26. FARRÉ, Josep Maria. «No hay perversión que valga». Ajoblanco, 34 (junio 1980), p. 40.

27. SETÉ, Joan. «Más de cien años de exhibicionismo». Los Marginados, 6 (diciembre enero 1978), p. 35.

28. Wittig, Monique. «La categoría de sexo». En El pensamiento heterosexual y otros ensayos, Madrid, Egales, 2006, pp. 21-29.

Feminismo/s 16, diciembre 2010, pp. 281-304 
la heterosexualidad normativa y a la defensa de un contínuum del deseo que anule las teorías hegemónicas de lo que Wittig denominaría el «pensamiento heterosexual». Serafín Senosiain defiende en un artículo para El Viejo Topo que la feminización aparente del «hombre travesti» supone una posibilidad de encuentro entre la identidad masculina y su propio cuerpo:

Ciertamente, en el travesti o el hombre afeminado encontramos algo atrayente en relación a la subversión de los roles preestablecidos, la destrucción de las fronteras impuestas sobre la conducta, que reprimen todas aquellas facetas indeseables, la eliminación de la rigidez del Macho, que queda destronada por el abandono festivo del cuerpo ${ }^{29}$.

En el revulsivo aparente que Senosiain propone, sin embargo, la mujer es utilizada como cuerpo mudo y sexuado, deviene una simple apariencia apropiada por el hombre que pretende reencontrarse con su propia sexualidad. Así percibido, este travesti en transición no renuncia a su condición de hombre, sino que utiliza su apariencia estereotipada de mujer para refigurar su propia identidad masculina. En el juego de máscaras travesti que nos ocupa, esta apariencia se formaliza como una ilusión que desnaturaliza las atribuciones de «género». No pretende, como argumentaba Severo Sarduy, la imitación de un «original»-la «mujer»- sino que revela la falsa naturalización de los elementos que se le atribuyen ${ }^{30}$. Para Sarduy, la simulación del travesti hace imposible la correspondencia entre modelo y representación, obliga, desde esta misma imposibilidad, a un cambio de perspectiva paralelo al que en el arte barroco instaura la anamorfosis. La coexistencia de dos perspectivas posibles, la pulsión de simulación, en palabras de Sarduy, es el juego que permite al travesti desequilibrar la dicotomía simbólica hombre/mujer y, por extensión, las estructuras de poder que la sostienen.

Los discursos sobre el travestismo recurrentes en las revistas contraculturales del posfranquismo pretenden apropiarse políticamente del potencial de esta pulsión, mostrar la inoperatividad de las categorías (de género) naturalizadas desde el poder hegemónico ${ }^{31}$. Defienden, así, un modelo teórico

29. Senosiain, Serafín. «En pos del andrógino». El Viejo Topo, 36 (1979), p. 56.

30. SARduY, Severo. La simulación. Venezuela, Monte Âvila Editores, 1982.

31. Una identificación entre travesti y transgresión se vincula también con algunos de los referentes estéticos y filosóficos de la intelectualidad alternativa del momento. Entre los referentes estéticos, el travestismo enlaza con distintas manifestaciones artísticas que se difunden durante los años sesenta y setenta -el action painting, el body art, el mimicry-dress art- y que convierten el propio cuerpo en espacio de representación, en marco, tela u hoja para la inscripción de la expresión creativa. Entre los referentes intelectuales podemos destacar la simulación barroca estudiada por Severo Sarduy pero también la política de la sexualidad de Michel Foucault. 
de transgresión que no insinúa sino que destapa su propio simulacro, un travesti que haga pública su impostura, enseñe así, simultáneamente, como lo hace Nazario en muchas fotografías de los primeros ochenta, combinaciones femeninas transparentes bajo las que se exhiben los genitales, o los labios y las uñas pintados en contraste con su espeso bigote ${ }^{32}$. De la misma manera, como han notado ya Josep-Anton Fernàndez y Teresa Vilarós ${ }^{33}$, algunas de las actuaciones de Ocaña que recoge el film Ocaña, retrat intermitent (1978), de Ventura Pons, se cierran con un striptease completo donde, mostrando los genitales, neutraliza la función de misterio o semiocultación que Esther Newton identifica en las manifestaciones de la performance $d r a g^{34}$.

$Y$ es que en la contracultura posfranquista, el travestismo se celebra solo cuando su impostura puede leerse abiertamente como una provocación, y no como un intento de disfraz. Su función política será operativa siempre que se presente como una parodia feminizada del poder-viril, y no como un intento pleno de conversión en «femenina» de una imagen «realmente masculina». Es así que Puig afirma que «pasa» de los travestis que se presentan como auténticas mujeres, el travesti «auténtico», argumenta, es sólo el que deja entrever su «falsedad»y, con ello, imposibilita la identificación de una manera «absoluta» de ser hombre o mujer: «el carmín de los labios y la barba, las medias

32. Se trata, como veremos, de una imagen que se aproxima a las que proponen las prácticas que serán designadas bajo la rúbrica «Gender Fuck», que pretenden desafiar las atribuciones de género a partir del juego con la presentación simultánea de elementos visibles atribuidos al género masculino o femenino. June L. REICH propone la siguiente definición de esta práctica: «Genderfuck could be said to be the effect of unstable signifying practices in a libidinal economy of multiple sexualities. The production of a recognizable genderfuck paradigm, effected by camp 'realness', alterns the contextual process of signification by foregrounding the gap between sex and gender and producing different models of interpretation through different writing/reading practices. Genderfuck, as a mimetic, subversive performance, simultaneously traverses the phallic economy and exceeds it» («Genderfuck: he law of the dildo». En F. Cleto (ed.). Camp. Queer Aesthetics and the Performing Subject: A Reader. Ann Arbor, The University of Michigan Press, 1999, p. 264). Sobre los discursos teóricos que fundamentan estas prácticas, ver también WhitTle, Stephen. «Gender Fucking of Fucking Gender? Current Cultural Contributions to Theories of Gender Blending». En R. Ekins; D. King (eds.). Blending Genders. Social Aspects of Cross-dressing and Sex-changing. Londres, Routledge, 1996, pp. 196-214 y NIETO, José Antonio. «Transgénero/Transexualidad: de la crisis a la reafirmación del deseo». En Transexualidad, transgenerismo y cultura. Madrid, Talasa, 1998, pp. 5-37.

33. FERNȦNDEZ, Josep-Anton. «The authentic queen and the invisible man: Catalan camp and its conditions of possibility in Ventura Pons's Ocaña, retrat intermitent». Journal of Spanish Cultural Studies, 5: 1 (2004), pp. 69-82. Vilarós, Teresa, Op.cit.

34. Newton, Esther, «Role Models». En F. Cleto (ed.). Camp. Queer Aesthetics and the Performing Subject: A Reader. Ann Arbor, The University of Michigan Press, 1999, p. 99.

Feminismo/s 16, diciembre 2010, pp. 281-304 
de seda sobre una piernas algo peludas, las espaldas anchas, más parecidas a los efebos de Miguel Ángel que a Marilyn Monroe, son elementos claves del mundo erótico del travestí para crear personajes que, a menudo, no excluyen ni a uno ni a otro sexo» ${ }^{35}$. Los verdaderos travestis, los revolucionarios, son también para Fernando Albertí los que hacen pública su condición de «hombres» bajo el maquillaje. Afirma así en un reportaje que ejemplifica de forma clara la apropiación simbólica del travesti como portavoz político, acomodado como hemos visto al ideario autonomista de la revista valenciana Dos y Dos:

Travestís operados, con sus tetas y todo, ya los habíamos visto en Valencia. Llega ahora, sin embargo, la nueva modalidad: el señor peludo y con pinta de camionero que se enfunda en una bata de volantes y se pone la cara perdida de rímel. Encarnita, Margot, Esmeralda y la Champán son además travestís antifascistas y críticos, travestís que «hacen país» desde el escenario ${ }^{36}$.

Se trata, significativamente, de una imagen del travesti radicalmente diferente a la que ofrecía Terenci Moix en el relato «Lilí Barcelona», escrito en 1965, donde el travesti resulta el símbolo por excelencia de un glamour a punto de desaparecer, de una elegancia que sólo tiene sentido como ideal, como un «misterio» que, cuando se hace público, provoca la desilusión e incluso la náusea. Describe así el protagonista su encuentro con la imagen ambigua y medio desnuda de Lilí, ya casi convertida en Jaume:

$\mathrm{Al}$ acercarme a una puerta muy pequeña, oí un ruido de seda y terciopelo que se estremecían. El corazón se me puso raudo. ¡Lilí! (Y mi boca rebosaba de misterio.)

Cuando abrí la puerta, Jaume se quitaba las medias. Ya se había liberado de la peluca rubio platino. No, sin embargo, de la pintura de los ojos. Me acaeció un sobresalto indefinido, que no tenía nombre. Ni tan solo en ese momento supe cómo era. Una sensación de vacío repentina, a la que siguió aquella náusea que no me ha abandonado nunca jamás ${ }^{37}$.

Para el protagonista del relato de Moix, la visión simultánea de Lilí y de Jaume en un solo sujeto provoca una sensación de vacío, un sobresalto que resulta, como la misma imagen transgénero, indefinido, innominable, nauseabundo, fruto de una ambigüedad que, cuando se muestra corre el riesgo de devenir monstruosa. La Barcelona simultáneamente abyecta y glamourosa de Moix no

35. Puig, Toni. Ibíd, p. 15.

36. AlBERTí, Fernando. Op.cit., p. 37. La expresión «hacer país», importada del catalán, se refiere al hecho de implicarse en los movimientos de defensa de la identidad nacional, aquí en concreto, en el proceso de movilizaciones a favor de un Estatuto de Autonomía para el País Valencià.

37. Morx, Terenci. «Lilí Barcelona». En Lilí Barcelona i altres travestís. Tots els contes, I. Barcelona, Edicions 62, 1978, p. 196. Traducción mía. 
sobrevive en el contexto contracultural que nos ocupa. En éste, para adquirir sentido, la práctica del travesti no puede ser sumergida sino que necesita precisamente hacer pública su impostura, señalar la distancia que existe entre la «máscara» de identidad superpuesta y la instancia que la luce. Es útil políticamente como símbolo de una resistencia a los roles impuestos por el poder franquista que empieza a poder expresarse a pie de calle.

\section{La difuminación de la frontera público/privado}

La función del travesti en la cultura de transición resulta, como hemos visto, la de visibilizar la posibilidad de subversión y la calle resulta en ella misma un espacio para reinventar desde su presencia ${ }^{38}$. En 1978, el encarcelamiento de Ocaña y Nazario en la prisión Modelo de Barcelona, por escándalo público, motiva un reportaje de Josep Vicent Rodríguez en la revista Valencia Semanal. Bajo el título «Los travestis tomaron la calle», los travestis que hemos visto que «hacían país» según un reportaje coetáneo de la revista Dos y dos, se pasean por el centro de Valencia y, según el cronista, haciéndolo, lo recuperan como espacio plenamente público: «La calle [...] es menos carca, mucho menos, de lo que nos quieren hacer creer. Y los travestis la tomaron. Y se metieron así en el bolsillo otra pequeña pero preciosa parcela de libertad $»^{39}$. El disfraz, explica el cronista, sirve para plantar cara al miedo de salir a la calle y hacer pública su identidad disidente: «El arte hay que hacerlo así, como decía Oscar Wilde, con la vida de uno, con uno mismo. Body art le llaman los modernos. Los travestis lo entienden, lo llevan y lo entienden ${ }^{40}$. La subversión se realiza mediante la exhibición de una intimidad antes oculta, como una denuncia a la hipocresía social que se manifiesta desde el simulacro autoproclamado del travesti.

Es por esto que, podríamos afirmar, si se me permite la broma, que los travestis barceloneses y valencianos de los que tratan estos artículos no salen «del armario» sino que salen más bien «al balcón». El balcón es un espacio limítrofe entre la vida privada y la vida pública, una posición desde donde manifestar la significación pública de la propia identidad, pero también una

38. He reflexionado ya sobre la equivalencia entre transición y ocupación de la calle en «Desconstruint Franco. El carnaval identitari de la transició». En Poètiques de ruptura. Teoria i pràctica del textualisme. Palma, Lleonard Muntaner Editor, 2008, pp. 77-110. Para una revisión de la función de la calle como espacio de disolución «del yo social de la posdictadura» ver Vilarós, Teresa. Op. Cit., pp. 218 y ss.

39. RodrígueZ, Josep Vicent. «Los 'travestis' tomaron la calle». Valencia Semanal, 35 (1978), p. 40.

40. Ibíd, p. 42.

Feminismo/s 16, diciembre 2010, pp. 281-304 
frontera entre el espacio privado atribuido a lo femenino y la presencia pública que durante el franquismo era vetada a las mujeres. No es así gratuito que sea un marco presente en la representación del pintor y activista José Ocaña que elabora Ventura Pons en la película documental Ocaña, retrat intermitent (1978). Resulta, también, una perspectiva privilegiada en numerosos dibujos y pinturas de Nazario, en las que, sobre todo los balcones de la Plaza Real se convierten en un espacio simbólico de la posibilidad de exposición pública de la vida privada. Así ocurre todavía en el cartel que Nazario realizaría para las fiestas de la Mercè de Barcelona el año 1999 -homenaje encubierto a Ocaña, que observa la fiesta sentado en una luna distante, y que causó una curiosa polémica al afirmar indignado el obispo de Barcelona, Ricard Maria Carles, que su diseño era de orientación «demasiado arabista» para mostrar las «raíces cristianas» de la ciudad, y aquí podríamos elucubrar si esta alteridad «arabista» que denunciaba el eclesiástico no escondía quizás otras alteridades referidas a otras «desviaciones católicas» más vinculadas con las políticas de género $^{41}$. Los balcones aparecen también en la portada de Plaza Real de Nazario, un volumen de crónicas dedicadas a este espacio público, donde la plaza y el travesti se convierten en sinónimos: «La Plaza Real tiene ese 'misterio' del travesti: tras la fachada de arcadas, palmeras y farolas de Gaudí, uno nunca sabe qué puede encontrar ${ }^{42}$.

Esta nueva Barcelona travesti es también en apariencia la ciudad marginal, la de la fiesta libertaria, la que subvierte las normas sexuales del franquismo y que rechaza un proyecto de transición política que, cada vez más, se presenta como reformista. Se trata, según escribe Fernando Mir en Ajoblanco, de «la Barcelona de la 'rauxa', la de la rebeldía, la marginada, la popular, la más desconocida en el resto del estado español, opuesta a la Catalunya del 'seny', la Cataluña exportable para la reforma $»^{43}$. Recorrer las fiestas alternativas de aquellos años es seguir los espectáculos con los que Ocaña, pero también sus amigos Nazario y Camilo, ocupaban los escenarios de las Jornadas Libertarias o del festival Canet Rock, vestidos de folclóricas o desnudos pero con tacones, en una concepción del carácter revolucionario de la fiesta que a menudo los organizadores de los actos no acababan de compartir. "Nos vamos porque estos son unos profesionales y nosotras unas pobres aficionás», afirmaba molesto Ocaña abandonado el escenario del Canet Rock. En la Barcelona de los setenta, sobretodo la Rambla deviene, como muestra la película de Ventura Pons, el espacio por excelencia donde llevar el teatro a la calle, en una

41. Ver «El arzobispo de Barcelona critica un cartel por arabista», El Mundo, 25-9-1999.

42. LUQUE, Nazario [Nazario]. Op.cit., p. 5.

43. Mir, Fernando. «Barcelona, ciudad de fiestas y marcha». Ajoblanco, 19 (1977), p. 17. 
performance continua de la que la ciudad pretendidamente marginal resulta el escenario privilegiado. Es, según la denominaría Guy Hocquenghem, «Barcelona-la-loca», una fiesta política donde intervienen con un papel destacado, afirma, «los mariquitas y las pelandruscas». Hocquenghem retrata el ambiente de la Rambla y también sus contradicciones, sobretodo, las que generan en los entornos homosexuales más politizados, que no siempre ven con buenos ojos los excesos de los travestis:

Ante el Café de la Ópera, un militante del FAGC me explica que los travestis del barrio chino son apolíticos. Sólo con echarle una mirada entiendo lo que dice. Los travestís no quieren convertirse en lo que él es: en homosexualesliberados-orgullosos-de-serlo-abstractos y politizados, machos castrados o hembras neutralizadas, ciudadanos responsables y futuras parejitas burguesas de acuerdo con el modelo de la publicidad liberal USA ${ }^{44}$.

El autor de Le désir homosexuel se hace eco del mito travesti barcelonés como espacio de resistencia y continúa afirmando:

Ellas, travestis y mariconas, saben que por debajo de los insultos que les lanzan por la calle late un sordo deseo, que su presencia despierta fuerzas intensas y ambiguas. En el mismo corazón del imperialismo macho, ellas son una herida permanente, irritante. Ellas no buscan la integración por medio de la política, sino que fuerzan las cosas sobre el terreno, la imponen en la calle y desde hace tiempo. Es normal, pues, que estos jovencitos que vienen a darles lecciones de militantismo sacadas de libros extranjeros no les caigan nada bien ${ }^{45}$.

Hocquenghem -de quien, por cierto, podían ser los libros «extranjeros» que leían los jóvenes militantes del Frente de Liberación Gay- describe Barcelona como una ciudad donde las tensiones sexuales son explosivas. Es en este marco de subversión, el que se niega a ser integrado, donde hay que buscar la posibilidad de una ruptura radical con el equilibrio sexual-político existente.

Ocaña se convertirá en el símbolo por excelencia de esta Barcelona con vocación de marginalidad, entre otras cosas, a causa de Ocaña, retrat intermitent, la película documental que le dedicaría Ventura Pons. Como ya han notado desde distintas posiciones Jaume Martí-Olivella o Josep-Anton Fernànde $z^{46}$, este film surge de una voluntad de revisar el juego a veces equívoco de asignaciones identitarias en la Cataluña del momento y su posibilidad

44. Hocquenguem, Guy. «Barcelona 'la loca' y sus liberadores homosexuales». El Viejo Topo, 8 (1977), p. 37.

45. Ibíd, p. 37.

46. Martí-Olivella, Jaume. «Ventura Pons o la teatralització de impostura». En J.A. Fernàndez (ed.). El gai saber. Barcelona, Llibres de l'Índex, 2000, pp. 373-392. FERNÀNDEZ, Josep-Anton. Op.cit.

Feminismo/s 16, diciembre 2010, pp. 281-304 
escenificación pública. Esta teatralización del conflicto identitario no sólo es fruto del juego de confesiones especulares a partir del que trabaja el documental de Pons, sino también de la percepción artística y vital que propone en su actuación pública y en su producción artística el mismo Ocaña. Ocaña refleja una forma de entender el arte, la creación, la provocación y la vida cotidiana implícita también en las performances del Living Theater, así como también con las ideas sobre el arte situacionista que ocupan los monográficos de las revistas contraculturales ${ }^{47}$. El situacionismo reclama la necesidad de subvertir el estado vigente desde la invención lúdica y la crítica a la vida cotidiana mediante la creación de nuevas situaciones inesperadas. Sea como referente directo o como contagio de un ambiente intelectual, la huella situacionista es útil para entender los famosos paseos travestidos de Ocaña, Nazario y Camilo por la Rambla como «desviaciones» que provocasen nuevas situaciones de ruptura, que desafiasen el orden establecido.

Se trata de transformar la calle, pero también de resituar el potencial revulsivo de la producción artística fuera de los museos, de difuminar la frontera entre espacio público y espacio privado. Desde esta perspectiva, resulta también pertinente que, al plantear una exposición de su obra para la sala Mec-Mec en 1977, Ocaña reproduzca en la sala de exposiciones su propia casa

En las paredes mujeres marginadas. Y marginados. Niños. Después, la Virgen en su capilla de flores y velas. [...] Más hacia el centro, una fuente de papel con agua de plata chocolate y dos gitanas sentadas, abanicándose. Con la cabeza de papel: Detrás, mi casa. Instalada tal como la tengo en [mi casa de] la Plaza Real. Con mi belén navideño. [...] Mi ropero. Abierto. Con guirnaldas de hojas secas por ropa. [...] Aquí sigo trabajando. Porque esto es ahora mi casa. Vienen mis amigos. Regalo a la gente mi casa y mi vida. Esto, Toni, no es un montaje. Aquí está todo lo que he recogido ${ }^{48}$.

Las descripciones de Ocaña, recuerdan, por otro lado, desde la figuración camp de objetos aparentemente folclóricos, la acumulación de objetos inconexos que elabora Severo Sarduy ${ }^{49}$ para construir los escenarios desde dónde reflexionar sobre la lógica del simulacro barroco. Las reflexiones sobre la propia tarea artística nos muestran una creación que va más allá de la pintura naïf a la que se ha ligado la producción pictórica de Ocaña, donde abundan las vírgenes, los personajes populares y las escenas cotidianas y festivas. Sus cuadros toman sentido en un contexto expositivo más amplio. Al situar su casa

47. Para la recepción en España, con algunos años de retraso, de las ideas situacionistas, ver el dossier «La vida cotidiana y su crítica», publicado en 1976 en Ajoblanco.

48. PUig, Toni. «Ocaña. La terrible ascensión de un marginado». Ajoblanco, 27 (1977), p. 21.

49. SARDUY, Severo. Op.cit.

Feminismo/s 16, diciembre 2010, pp. 281-304 
en la sala de exposiciones y su arte transvestista en la calle, trastoca también los límites entre el espacio íntimo o doméstico (el «hogar» que para Primo de Rivera era el reino de la mujer) y el espacio público (calle o sala de exposiciones) donde mostrarse. Se trata, podríamos pensar, de una percepción también transvestida del espacio artístico, donde lo femenino-doméstico se filtra en los territorios del poder masculino-público.

\section{Paréntesis: Ocaña o los riesgos de la integración}

Travestirse, para Ocaña, no es ni una perversión ni un comportamiento patológico, sino un juego creativo más que los intelectuales están llenando de sentido político. Afirma en una entrevista: «Mi autodefensa podría ser el travesti. Como el intelectual se coge a la semiótica $»^{50}$ y añade dos años después, desafiando a los críticos que intenten llenar de significados su práctica: «[Travestirme] me ha gustado siempre. Ya mi padre se travestía en los carnavales y muchos lo hacen sin darle la mayor importancia. Ahora vienen los 'progres' y se ponen a decir tonterías. Lo que pasa es que se les ha atragantado el Freud de bolsillo que leen $»^{51}$. Esta carga de sentido político a la subversión travesti como símbolo de una época transcenderá los límites del ambiente contracultural con la película documental Ocaña, retrat intermitent (1978) de Ventura Pons. Me interesa notar, más que el lenguaje de la película en sí, que ya ha sido analizado por otros, cómo la misma película sitúa a Ocaña en un espacio incómodo en el que se le atribuyen representatividades que no ha reclamado. Así ocurre en las distintas críticas de Ocaña, retrat intermitent. Para Terenci Moix, es el primer retrato auténtico de la España del posfranquismo; resulta la película, según la crítica de José Luís Guarner para Interviu, donde mejor se respira un ambiente posfranquista. Todavía a finales de los noventa, Àngel Quintana la describiría como «uno de los más preciados documentos sobre el estallido y la muerte de esa Barcelona libertaria que se forjó en la calle, al margen de los discursos oficiales $\aleph^{52}$. El travestismo teatral de Ocaña deviene símbolo de una revuelta condenada a la integración, un símbolo que parece que tampoco fue bien acogido por ciertos sectores del FAGC (Front d'Alliberament Gai de Catalunya), lo que afecta a Ocaña, quien afirma en una

50. Puig, Toni. «Ocaña. La terrible ascensión...», Op.cit., p. 22.

51. PUIG, Toni. «Ocaña. La espontaneidad contra la integración». Ajoblanco, 36 (1978), p. 45.

52. Las reseñas a la obra pueden consultarse en la página web del director Ventura Pons $<$ www.venturapons.com>.

Feminismo/s 16, diciembre 2010, pp. 281-304 
entrevista: «En este país, la envidia está suelta. A mí me sabe muy mal que haya una parte de homosexuales que no me puedan ver y me pongan verde» ${ }^{53}$.

La proyección de la imagen travestida de Ocaña como símbolo de los espacios de libertad que permitió la muerte de Franco situará al mismo Ocaña en el centro del debate sobre cómo resituar esta subversión ante el poder que se afirma en el nuevo marco democrático. A la larga, una pregunta recurrente en el entorno contracultural del momento pasará a tener a Ocaña en su punto de mira: ¿se integrará en el sistema que pretendía transgredir? Escribe Toni Puig para Ajoblanco:

¿Está integrado el Ocaña? Muchos han pretendido promocionarlo invitándolo como showman para que anime sus mortuorias fiestas en las que nadie tiene nada que contarse. Las revistas de pro del país lo presentan en sus páginas como un producto exótico de la contracultura. De esa contracultura que ya no duele. Porque la manzana, finalmente se comió el gusanillo. [...] Ocaña representa, creo, un ecosistema de vida por el que muchos nos hemos movido. Y nos movemos. Sin demasiado dinero. Confiando en los amigos. Con mucha vida de café. Sintiéndonos vivos. Con ganas de transformar ese pastel de mierda ciudadano. ¿Se integrará? ¿Ya lo está? ¿Nos integraremos? ¿La marginación ascenderá terriblemente al paraíso de las mercancías? ${ }^{54}$

Y comenta el mismo Ocaña sobre el tema hablando de los que han estado criticando su posición: «Esas que no se crean que me pueden marginar tan fácilmente. Ahora, si ellos, después de lo que digo en la película, lo integran, a ver quién integra a quién ${ }^{55}$. La postura de Ocaña ante la espada de Damocles de la integración no deja de ser interesante: para él, una cosa es integrarse y otra que integren su discurso por causa de su influencia y esto último, influir sobre el desarrollo de los discursos ajenos, no tiene por qué ser negativo. «Como la gente necesita un mito, el mío se lo han montado un poco entre todos» ${ }^{56}$, afirma en una entrevista donde se le presenta como un personaje que se niega a aceptar el papel que se le ha otorgado: el del travesti oficial de las Españas de la transición a la democracia.

A la larga, la muerte de Ocaña a los treinta y seis años fomentó una mitificación mucho más minoritaria. Las circunstancias de su muerte, propiciada por las quemaduras causadas por una bengala cuando iba disfrazado de «rey sol» en el carnaval de su pueblo, motivaron una canción de Carlos Cano («Romance a Ocaña», 1985), así como la obra de teatro Ocaña, el fuego infinito (1987), de Andrés Ruiz, para la que Nazario había hecho algunos

53. En PuiG, Toni. «Ocaña. La espontaneidad...», Op.cit., p. 48.

54. Puıg, Toni. «Ocaña. La terrible ascensión...», Op.cit., p. 23.

55. En Puig, Toni. «Ocaña, la terrible ascensión...», Op.cit., pp. 48-49.

56. En S/n. «Un huracán llamado Ocaña». Valencia Semanal, 46 (1978), p. 44. 
borradores de decorados. De hecho, Nazario será quien más presente hará la figura de Ocaña en su constante recreación pictórica de los espacios de Barcelona. Ocaña aparece así «beatificado» en «La ascensión de Ocaña al reino de los chulos» (1984) y motiva el escenario de algunas de sus pinturas de los años noventa, como la acuarela «Vanitas u Ocaña y los siete sentidos» (1997), una de las muchas naturalezas muertas de objetos disímiles y desordenados que habitan su pintura.

\section{Conclusiones: ¿de la simulación al montaje?}

Pretendía sencillamente en estas páginas presentar algunos datos sobre la apropiación simbólica de la figura del travesti en los discursos alternativos que se producen durante la transición a la democracia. El travestismo se concibe como una práctica con la que visibilizar la voluntad de ruptura con un orden político y cultural heredero del franquismo, una manera de anular un poder que se caracterizaba como viril sin llegar a construir otro poder operativo, sino mostrando únicamente sus fisuras. En la prensa contracultural, lo travesti no se presenta como una práctica, ni una opción, sino más bien un símbolo de contrapoder adecuado para ejemplificar la clausura de la «virilidad» del poder franquista sin afirmar todavía plenamente una nueva identidad democrática. Resulta, por lo tanto, un correlato útil para visibilizar la necesidad de celebrar la posibilidad de subversión, de exorcizar las huellas que el poder franquista pueda haber impreso, más allá de las instituciones, en la percepción de la propia identidad o las posibilidades de ocupar el espacio público. Sin embargo, como emblema apropiado, no dará cuenta de la experiencia «real» de las opciones transgénero, de su propia posición en el espacio público o de su marginación en la legislación que se inaugurará con la democracia.

A la larga, esta imagen simbólica o emblemática del travesti acabará integrándose en el nuevo sistema de poder que aparentemente rehúye. Películas como Cambio de sexo (1977), de Vicente Aranda, presentarán las identidades transgénero desde la patología. Ocaña no sería, como temían los libertarios de Ajoblanco, el travesti oficial de la transición, un lugar que correría a ocupar Bibi Andersen, icono de la feminidad espléndida y morbosa en los años del destape, que afirmaba el año 1979 en la revista Valencia Semanal «soy un montaje». La fuerza subversiva del imaginario travesti en la contracultura de la transición se desvanece en la declaración provocadora de la «chica Almodóvar», el montaje desconoce la capacidad de subversión de la simulación atribuida a la posición del travesti, resulta, más que un espejismo sobre la imposibilidad de definir sin fisuras los atributos que determinan una identidad de género, un objeto espectacular, cuyo lugar deja de ser la calle para volver 
a ser la pantalla o el escenario recluido, deja de convertir el espacio público en el gran teatro del mundo, para encontrar un papel en el mundo del teatro.

\section{Referencias bibliográficas}

AlberTí, Fernando. «Travestis que hacen país». Dos y Dos, 50 (1977), pp. 37-39. BOURDIEU, Pierre. La dominación masculina. Barcelona, Anagrama, 2000 (1998).

ButLER, Judith. Gender Trouble. Feminism and the Subversion of Identity. New York, Routledge, 1990.

CAMAÑAS, Benigno. «El travestismo resucita». Los Marginados, 8 (1978), pp. 30-31.

CARDín, Alberto; JimÉnez-Losantos, Federico. La revolución teórica de la pornografía. Barcelona, Iniciativas Editoriales, 1978.

DD.AA. Nazario. Barcelona 1972-2002. Barcelona, Electa, 2002.

FARRÉ, Josep Maria. «No hay perversión que valga». Ajoblanco, 34 (junio 1980), pp. 40-41.

FERNÀNDEZ, Josep-Anton. «The authentic queen and the invisible man: Catalan camp and its conditions of possibility in Ventura Pons's Ocaña, retrat intermitent». Journal of Spanish Cultural Studies, 5: 1 (2004), pp. 69-82.

FOUCAULT, Michel. «Les rapports de pouvoir passent à l'intérieur des corps». En Dits et écrits: 1954-1988. París, Galimard, 1994, pp. 228-236.

Gallego MÉndez, María Teresa. Mujer, falange y franquismo. Madrid, Taurus, 1983.

Garlinger, Patrick Paul. «Dragging Spain into the Post-Franco's Era: Transvestism and National identity in Una mala noche la tiene cualquiera». Revista Canadiense de Estudios Hispánicos, XVIV: 2 (2000), pp. 363-381.

GoNZÁLEZ AJA, Teresa. «Monje y soldado. La imagen masculina durante el Franquismo». Revista Internacional de Ciencias del Deporte, 1 (2005), pp. 64-83.

Heller, Agnès. «El futuro de las relaciones entre los sexos». El Viejo Topo, 26 (1978), pp. 9-15.

HocQuenguem, Guy. «Barcelona 'la loca' y sus liberadores homosexuales». El Viejo Topo, 8 (1977), p. 37.

LUQUE, Nazario [Nazario]. Plaza Real. Madrid, Vossa, 1995.

MARTí-Olivella, Jaume. «Ventura Pons o la teatralització de impostura». En J.A. Fernàndez (ed.). El gai saber. Barcelona, Llibres de l'Índex, 2000, pp. 373-392.

MESAllES, Jordi. «Travesti: gesto y deseo». El Viejo Topo, 12 (1977), pp. 64-66.

MIR, Fernando. «Barcelona, ciudad de fiestas y marcha». Ajoblanco, 19 (1977), p. 17.

Morx, Terenci. «Lilí Barcelona». En Lilí Barcelona i altres travestís. Tots els contes, I. Barcelona, Edicions 62, 1978, pp. 179-198. 
Newton, Esther. «Role Models». En F. Cleto (ed.). Camp. Queer Aesthetics and the Performing Subject: A Reader. Ann Arbor, The University of Michigan Press, 1999, pp. 96-109.

NiETO, José Antonio. «Transgénero/Transexualidad: de la crisis a la reafirmación del deseo». En Transexualidad, transgenerismo y cultura. Madrid, Talasa, 1998, pp. 5-37.

OlmedA, Fernando. El látigo y la pluma. Homosexuales en la España de Franco. Madrid, Oberon, 2004.

PÉREZ-SÁNCHEZ, Gema. «El Franquismo ¿un régimen homosexual?». Orientaciones, 7 (2002), pp. 29-48.

PiCORNELl, Mercè. «Desconstruint Franco: el carnaval identitari de la transició». En Poètiques de ruptura. Teoria i pràctica del textualisme. Palma, Lleonard Muntaner Editor, 2008, pp. 77-110.

Pons, Rafa. «Confesiones de un travesti». Los Marginados, 8 (1977), pp. 22-23.

PUIG, Toni. «Yo también soy travesti». Ajoblanco, 19 (1977), pp. 13-16.

— «Ocaña. La terrible ascensión de un marginado». Ajoblanco, 27 (1977), pp. 21-23.

— «Ocaña. La espontaneidad contra la integración». Ajoblanco, 36 (1978), pp. 48-51.

R. A. «No hay perversión que valga». Ajoblanco, 34 (1978), pp. 40-41.

RAMON, José. «Diccionario-guía de perversiones e inventario de aberraciones». Ajoblanco, 17 (1980), pp. 68-71.

REICH, June L. «Genderfuck: he law of the dildo». En F. Cleto (ed.). Camp. Queer Aesthetics and the Performing Subject: A Reader. Ann Arbor, The University of Michigan Press, 1999, pp. 254-265.

RODRíGUEZ, Josep Vicent. «Los 'travestis' tomaron la calle». Valencia Semanal, 35 (1978), pp. 40-41.

Ruiz LÓPEZ, Andrés. Ocaña, el fuego infinito. Madrid, La avispa, 1987.

S/n. «Un huracán llamado Ocaña». Valencia Semanal, 46 (1978), pp. 44-45.

SARDUY, Severo. La simulación. Venezuela, Monte Ávila Editores, 1982.

SENOSiAin, Serafín. «En pos del andrógino». El Viejo Topo, 36 (1979), pp. 54-61.

SETÉ, Joan. «Más de cien años de exhibicionismo», Los Marginados, 6 (diciembre enero 1978), pp. 33-35.

TRENC, Eliseo. «Nazario, un geni adult del còmic». En DD.AA. Nazario. Barcelona 1972-2002. Barcelona, Electa, 2002, pp. 25-30.

UGARTE, Javier. «Entre el pecado y la enfermedad». Orientaciones, 7 (2004), pp. 7-26.

VINCENT, Mary. «La reafirmación de la maculinidad en la cruzada franquista». Cuadernos de Historia Contemporánea, 28 (2006), pp. 135-151.

VILARÓs, Teresa. El mono del desencanto. Una crítica cultural de la transición española (1973-1993). Madrid, Siglo XXI, 1998.

Feminismo/s 16, diciembre 2010, pp. 281-304 
Whittle, Stephen. «Gender Fucking of Fucking Gender? Current Cultural Contributions to Theories of Gender Blending». En. R. Ekins; D. King (eds.). Blending Genders. Social Aspects of Cross-dressing and Sex-changing. Londres, Routledge, 1996, pp. 196-214.

WitTig, Monique. «El pensamiento heterosexual». En El pensamiento heterosexual y otros ensayos. Madrid, Egales, 2006, pp. 45-57.

- «La categoría de sexo». En El pensamiento heterosexual y otros ensayos, Madrid, Egales, 2006, pp. 21-29. 